\title{
What is The Impact of Excessive lodine and Semen Quality in Fertile Men of China: An Association Study
}

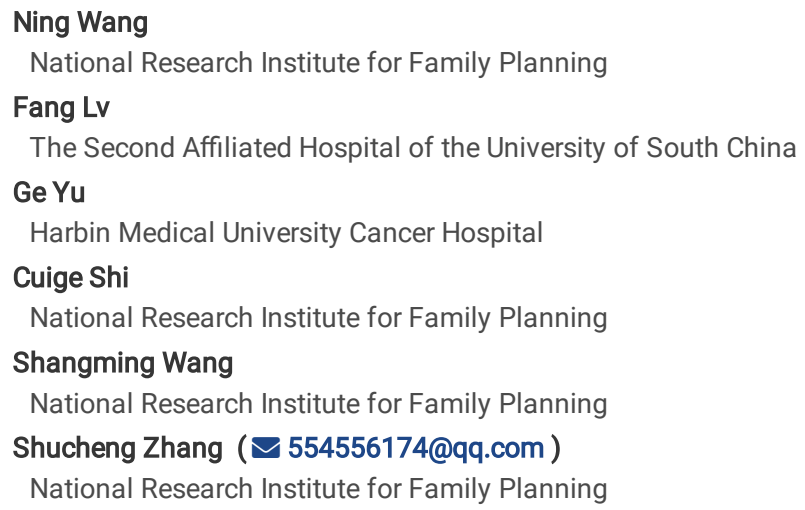

Research

Keywords: UIC, semen quality, semen concentration, total sperm count, TTP

Posted Date: February 25th, 2021

DOI: https://doi.org/10.21203/rs.3.rs-230463/v1

License: (c) (1) This work is licensed under a Creative Commons Attribution 4.0 International License. Read Full License 


\section{Abstract}

Background: lodine is an essential element for hormones synthesized by the human thyroid gland. Thyroid hormone deficiency affects all body tissues, including multiple endocrine changes that alter growth hormones, corticotrophin, glucocorticoids, and gonadal function. In many countries, subfertility is an important problem affecting about $10-15 \%$ of all couples trying to conceive. Male subfertile factors have accounted for $25-30 \%$ of all cases in their studies. The aim of this study was to study the correlation between urinary iodine concentration (UIC) and semen quality of fertile male in China.

Methods: semen and urine samples were collected from males who attended a survey for the reproductive physiological constants of male and female in China. All participants were fertile and they should be free from diseases of male reproductive system and thyroid related diseases. We studied the correlation between UIC and semen quality parameters in fertile males and the effect of iodine concentration on male reproduction. Participants were divided into six groups based on UIC. We measured semen parameters and UIC. Semen parameters or time-to-pregnancy (TTP) were analyzed by Spearman correlation, linear regression and multivariable logistic regression.

Results: 1089 men were recruited in the study. The mean and median age of participants were $27.46 \pm 0.12$ and $27 \pm 3.88$ years, respectively. UIC of 274 $(25.16 \%)$ men was lower than the UIC of WHO recommended. UIC of 405 men located in the region of WHO recommended. $62.35 \%$ of them were not located in the optimal region. Semen concentration and total sperm count were found to decrease when UIC increases when the UIC $\geq 100 \mathrm{ug} / \mathrm{L}$.

Conclusions: A male with deficient UIC or excessive UIC has more risk of lower semen quality such as sperm concentration and total sperm count. In addition, if a male with deficient UIC or excessive UIC, his wife has longer TTP than the males who had normal UIC. Deficient UIC associated with lower semen quality and TTP than excessive UIC.

\section{Background}

lodine is an essential element for hormones synthesized by the human thyroid gland (lodine Global Network; Zimmermann and Andersson, 2012). Previous research has found that thyroid hormone deficiency affects all body tissues, including multiple endocrine changes that alter growth hormones, corticotrophin, glucocorticoids, and gonadal function (Meikle, 2004). When iodine intake is insufficient, goiter incident is high and causes brain damage in fetuses and children, or possibly is responsible for psychomotor retardation (Rasmussen et al., 1999). After the discovery of the relationship between goiter and iodine deficiency, iodine supplements were used to prevent this disease in many countries. Salt iodization was implemented against goiter in China beginning in 1995. The incidence of goiter by palpation declined year after year in 8- to 10-year-old children. One study found that the average intelligence quotient (IQ) of 8- to 10-year-olds was 103.4 and remained at a normal level (Xiao et al., 2005). In studies in Colombia and Brazil, however, $43 \%$ and $86 \%$ of schoolchildren, respectively, were found to have excessive urinary excretion of iodine (Carvalho et al., 2012; Rossi et al., 2001). Several studies have found that both insufficient and excessive iodine are harmful to humans (Guo et al., 2016; Leung and Braverman, 2014; Teng et al., 2006).

In addition, excessive iodine also has been found to have an effect on male fertility, given the coincidence of declining sperm count with iodine supplementation in the United States, France, and the United Kingdom (Partal-Lorente et al., 2017; Sakamoto et al., 2004).

In many countries, subfertility is an important problem affecting about $10-15 \%$ of all couples trying to conceive (Evers $\mathrm{JL}, 2002)$. Male subfertile factors have accounted for $25-30 \%$ of all cases in their studies (Hammiche et al., 2012). Semen quality parameters have been used as an alternative index representing male fertile status. Time-to-pregnancy (TTP) was the optimal assessment index to determine male fertility (Vieria, 2010).

Given these findings, we aimed to assess the association between UIC and semen quality in normal fertile men of China and to investigate the association between urinary iodine levels and TTP in normal fertile Chinese men.

\section{Methods}

\section{Study design and population}

This survey was conducted at six administrative regions in China, from 2013 to 2017. Volunteers completed questionnaires about personal information, pregnant history, birth history, medical history, and medication history with help from research assistants.

All of the participants had to meet the following inclusion criteria: All female partners were naturally pregnant at the survey time and lived in the study region full time. Male partners were more than 18 years old, agreed to a 2- to 7-day abstinence period, and ate a normal diet without any additional iodine for 2 weeks before the investigation. The exclusion criteria were as follows: known thyroid disease (hyper- or hypothyroidism or autoimmune disease), chronic disease history, sexually transmitted disease, urinary or reproductive system disease (inflammation of reproductive system, malformation, cryptorchidism, and varicocele), potential dangerous occupation (petroleum and chemical industry, high temperature or high humidity environment), and high-risk exposure of reproductive toxins such as benzene, gasoline or diesel, aldehyde ether, organic solvent, volatile solvent, radiation, electromagnetic, and radar (Virtanen et al., 2017). If the volunteer had any one of the criteria, he was excluded from the investigation.

\section{Ethical approval}

We obtained institutional review board approval from the Academic Committee of the National Research Institute for Family Planning on the use of Human Subjects in Medical Research. All volunteers provided written informed consent.

\section{Semen collection and analysis}


Each participant underwent a physical examination on the day of semen collection. Volunteers provided their semen samples as instructed by clinicians in a private room near the laboratory. Samples were collected in a wide-mouthed clean and clear plastic container. We analyzed semen samples within the first hour after collection and assessed semen quality according to the criteria of the World Health Organization (WHO) standardized methods. We analyzed the $\mathrm{pH}$, volume, density, total sperm count, spermatozoa with progressive and nonprogressive motility, immobile spermatozoa, and total motile sperm count following the guidance of the WHO (World Health Organization, 2010). In addition, two professional physicians verified and confirmed all sperm motility analyses using videos after on-site analysis.

\section{Laboratory determinations}

At least $20 \mathrm{ml}$ urinary samples were collected on-site and frozen at $-20^{\circ} \mathrm{C}$ until laboratory analysis. We measured all urinary samples using the same batch of kits. We measured UIC using a modification method based on Sandell-Kolthoff reaction (Pino et al., 1996).

\section{Statistical analysis}

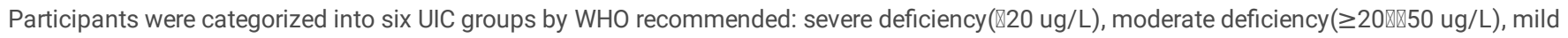

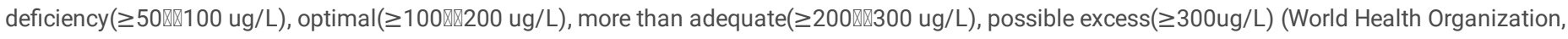
$1999,2007)^{[20,21]}$. We presented categorical variables as absolute and relative frequencies and continuous variables as median values (25th, 75th percentiles). Chi-square tests were used to compare categorical variables. The differences between the three UIC groups and the various sperm parameters were compared according to the Kruskal-Wallis test. We conducted linear regression (when the outcome was continuous) or multivariable logistic regression (when the outcome was dichotomous) to assess the association between UIC categories and semen parameters or TTP using random intercept models (Michael L, $2014)^{[22]}$. All regression models were adjusted for the following confound factors: age, body mass index (BMI), period of abstinence, alcohol consumption, smoking status, and education level. We considered confidence intervals that excluded one- or two-tailed P-values of $<0.05$ to be statistically significant. We performed all statistical analyses using the SPSS 19 software package (SPSS, Inc., Chicago, IL, USA).

\section{Results}

\section{Characteristics of participants}

The general characteristics of 1089 men are provided in Table 1. UIC of 274 (25.16\%) men was lower than the optimal UIC of WHO recommended. UIC of 405 men were higher than the optimal UIC of WHO recommended. $62.35 \%$ of them were not located in the optimal region.

\section{Reproductive relative parameters and semen parameters}

Reproductive relative and semen parameters of 1089 subjects are showed according to UIC grouping in Table 2. The wives of all the participants are being pregnancy. About $7 \%$ has more than 3 pregnant history $22.3 \%$ participants have more than one child. $5.1 \%$ couples have more than 12 months TTP. The sperm concentration (95.8\%) and total sperm count (94.7\%) were located in normal regions according to the WHO standard. 855 (78.51) samples had all normal semen parameters in 1089 participants.

\section{Association between higher UIC and semen parameters}

We found a linear association between excessive UIC and an increased incidence of low semen concentration ( $<15 \mathrm{M} / \mathrm{ml})$ and low total sperm count ( $<39 \mathrm{M})$ (see Table 3, 4).

After unadjusted and adjusted multivariable logistic analyses, the relative risk for excessive UIC with abnormal parameters was significant in semen concentration and total sperm count. Men with excessive UIC had 18.53 times higher odds of having a low semen concentration (95\% $\mathrm{Cl} 4.20-81.73)$. When a man had excessive UIC, he had an 8.64 times higher odds of also having a low total sperm count (95\% $\mathrm{Cl} 3.07-24.34)$. In semen pH, however, excessive UIC was a protective factor $(95 \% \mathrm{Cl} 0.48-0.98)$. If a man had excessive UIC, he had a more normal semen $\mathrm{pH}$ than other men (see Table 5).

\section{Association between higher UIC and TTP}

The average and median TTP were 4.569 and 3 months, respectively. TTP range was from 1 to 36 months. TTP increased with UIC, the unadjusted and adjusted regression coefficients were $r=0.251(P=0.000)$ and $r=0.253(P=0.000)$, respectively. According to logistical analyses, when a male had excessive UIC, his wife had 7.49 times higher risk of longer TTP (95\% Cl 3.34-16.80; 95\% Cl 3.37-16.00) in unadjusted and adjusted models, respectively (see Table 3$5)$.

\section{Association between deficiency UIC and semen parameters}

We found a linear association between deficiency UIC and an increased incidence of low semen concentration ( $<15 \mathrm{M} / \mathrm{ml})$ and low total sperm count ( $<39 \mathrm{M}$; see Table 6, 7).

After unadjusted and adjusted multivariable logistic analyses, the relative risk for deficient UIC with abnormal parameters was significant in semen concentration and total sperm count (see Table 7). This trend was depended on the UIC. The lower UIC associated with more risk for decreased semen quality once UIC was deficiency. When the UIC was severe, moderate, or mild deficiency, men had 22.84 (95\% $\mathrm{Cl} 1.86-269.95), 18.66$ (95\% $\mathrm{Cl} 3.35-98.54)$ and 19.40 $(95 \% \mathrm{Cl} 4.46-84.45)$ times higher odds of having a lower semen concentration than $15 \times 106 / \mathrm{ml}$. When a man had severe, moderate, or mild deficient UIC, he 
had 20.00 (95\% Cl 3.36-118.94), 9.06 (95\% Cl 2.67-30.70) and $9.13(95 \% \mathrm{Cl} 3.39-24.55)$ times higher odds of having a lower total sperm count than $39 \times 10^{6}$ (see Table 8).

\section{Association between deficient UIC and TTP}

The average and median TTP were $5.367 \pm 4.97$ and 3 months, respectively. TTP range was from 1 to 55 months. TTP decreased with UIC, the unadjusted and adjusted regression coefficients were $r=0.299(P=0.000)$ and $r=0.327(P=0.000)$, respectively. According to logistical analyses, When a man had severe, moderate, or mild deficient UIC, his wife had 16.93 (95\% Cl 3.81-75.19), 11.63 (95\% Cl 4.63-26.89) and 8.67 (95\% Cl 4.23-17.89) times higher risk of longer TTP in unadjusted models. The same trend was also showed in adjusted models (see Table 6-8).

\section{Discussion}

Public health problems induced by excess iodine are now emerging in many iodine-sufficient regions (Partal-Lorente et al., 2017). In this study, we investigated the association between UIC and semen parameters for normal fertile men in Han, China. The study showed a relationship between deficient or excessive UIC and low semen concentration and total sperm count in semen parameters. When UIC was in deficient or excess, men had a higher incidence of low semen concentration and low total sperm count.

Few studies have reported the association between iodine and semen quality, especially in fertile populations. In 1992, it was reported that semen quality had declined gradually over the past 50 years (Carlsen et al., 1992). Swan reanalyzed data from 61 studies and used multiple linear regression and nonlinear models, which supported a significant decline in semen density. As a result, an environmental factor was deemed to be clearly warranted in addition to regional and temporal differences (Ebisch et al., 2008; Jorgensen et al., 2001; Swan et al., 1997; 2000). Sakamoto also reanalyzed the studies about semen quality decline. The semen total sperm count density changed with different decades before and after iodine supplementation in the United States. Total sperm count in the United States increased starting in 1934 after iodine supplementation began in 1924. The trend of increasing sperm count in the United States began to change between 1965 and 1969. Similar results were found in Paris, France, and in Britain. In Toulouse, France, however, no sperm count alteration was exhibited. Toulouse faces the Mediterranean Sea, and adequate iodine intake was obtained from seafood. Similarly, because of the habit of eating seafood, sperm count had not altered in the past year in Japan. Based on these studies, this sperm count trend appeared to be consistent with iodine supplementation (Sakamoto et al., 2004). In 2017, adequate iodine intake associated with semen quality in men was proven by Partal-Lorente et al (PartalLorente et al., 2017). In this study, men with high semen iodine levels had more morphological sperm. Men with higher urinary iodine levels had lower motile sperm count. The participants came from 96 couples consulting for infertility at the Assisted Reproduction Unit of the hospital.

In another study, UIC was the prime indicator of iodine status in a population and was used to assess the nature and timeliness of salt iodization (Rohner et al., 2014). Our study focused on the association between excessive UIC and semen quality. We used UIC an indicator to analyze the association of semen quality of fertile men in China. Our study had some differences from other studies. The participants were proved fertile because their partners were pregnant. They all were Hans and came from different regions of China. UIC has been associated with semen concentration and total sperm count in different statistical models. We did not determine total sperm count to be an independent semen parameter because it was the calculated product of semen concentration and semen volume. Excessive UIC posed greater risk with a lower semen concentration and lower total sperm count. According to research, the possible effect of excess iodine on spermatozoa was lower in humans than in animals. Some animal studies might explain the harmful effects of excessive iodine on sperm parameters. Oxidative stress was a proven male factor for subfertility because of its damaged semen quality (Ebisch et al., 2008). Increased oxidative stress could be generated after excess iodine intake (Chakraborty et al., 2016). In a rat study, excess iodine intake increased reactive oxygen species. As a result, iodine affected male fertility potentially by initiating apoptosis in spermatozoal cells (Mahapatra and Chandra, 2017).

This study had three limitations. First, we analyzed only one semen sample from each volunteer. Considering the study was investigated in a normal fertile population, one sample was suitable to assess semen quality in an epidemiological study (Stokes-Riner et al., 2007). Second, we randomly collected urinary samples on-site. Third, some important semen parameters, such as sperm DNA fragmentation, could not be analyzed because of poor laboratory conditions in some investigation fields. Forth, some Cls were wide, reflecting small sample sizes for select variables.

\section{Conclusion}

In this study, we associated deficient or excessive UIC with harmful effects on semen quality, which affected the TTP in the fertile male in China. Many studies have focused on the clinical manifestation of thyroid hormone deficiency, whereas few studies have shown that excessive iodine intake is related to male reproduction. Our results indicated that iodine may play a role in semen quality or male reproduction. Men with deficient or excessive UIC are associated with low semen density and low total sperm count. Deficient or excessive UIC associated with lower semen quality and TTP than excessive UIC. This profile requires additional studies to fully explain the role iodine may play in male reproduction.

\section{Abbreviations}

BMI: Body Mass Index; UIC: urinary iodine concentration; TTP: time-to-pregnancy;

PR: progressive spermatozoa; NP: nonprogressive spermatozoa; IM: immobile spermatozoa,

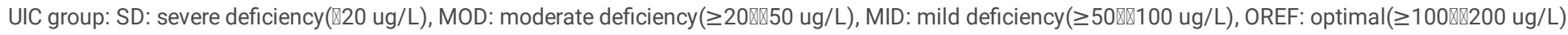

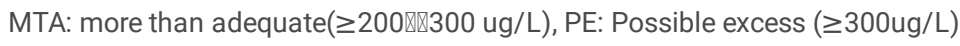




\section{Declarations}

\section{Ethics approval and consent to participate}

The study was approved by the Ethics Committee of the National Research Institute for Family Planning. All participants were informed about this study and signed consent forms before completing the questionnaire, agreeing to donate the sample of semen and a random sample of midstream specimen of urine the use in the current scientific research.

\section{Consent for publication}

Not applicable.

\section{Availability of data and materials}

The datasets analyzed is available from the corresponding author on reasonable request.

\section{Competing interests}

The authors do not have any conflicts of interest to declare.

\section{Funding}

This study was funded by the Special Foundation for State Basic Research Program of China (2013FY110500, 2013FY110511); Developing Science and Education Foundation of Second Affiliated Hospital of Soochow University (XKTJ-RC202002).

\section{Authors' contributions}

NW and SCZ conducted the data analyses and manuscript writing; NW and FL designed the study and the outline of the manuscript; SCZ designed the questionnaire, GY and SMW collected the data. All authors read and approved the final manuscript.

\section{Acknowledgements}

The authors would like to thank the survey project teams of the reproductive physiological constants of male and female in China. Team of Heilongjiang: Laifa Liu, Yuhua Sun, Chuanhui Zhao, and Chunxue Miao; Team of Henan: Zizhou Zhang, Xiaobo Meng, Zhiwei Guo, and Haizhou Guo; Team of Guangxi: Danni Xie, Yi Mo, Daxian, Tan, and Futong Lv; Team of Hebei: Xiaoqun Liu, Shuxiu Song, Suming Duan, and Fujun Li; Team of Zhejiang: Jianhui Li, Lihua Zhuang, and Xiaohua, Yu; Team of Xinjiang: Li Liu, Xiaoyan Shen, and Aiping Ma; Team of Jiangxi: Qishen Zhong; Team of Shanghai: Yihua Gu, Bin Wu, Miao Liu, and Yao Yuan; and Team of Beijing: Bin Zhang, Jingcui Bai, Lei Zhang, Guo Bao, Yu Gao, Gang Wei, and Bin He.

\section{References}

1. Carlsen E, Giwercman A, Keiding N, Skakkeblek NE, Evidence for decreasing quality of semen during past 50 years $B M J 1992 ; 305: 609-613$.

2. Carvalho AL, Meirelles CJ, Oliveira LA, Costa TM, Navarro AM. Excessive iodine intake in schoolchildren. Eur J Nutr. 2012;51:557-62.

3. Chakraborty A, Mandal J, Mondal C, Sinha S, Chandra AK. Effect of excess iodine on oxidative stress markers, steroidogenic-enzyme activities, testicular morphology and functions in adult male rats. Biol Trace Elem Res. 2016;172:380 394.

4. Ebisch IM, Thomas CM, Wetzels AM, Willemsen WN, Sweep FC, Steegers-Theunissen RP. Review of the role of the plasminogen activator system and vascular endothelial growth factor in subfertility. Fertil Steril. 2008;90:2340-50.

5. Evers JL. Female subfertility. Lancet. 2002;360:151-9.

6. Guo Y, Zynat J, Xu Z, Wang X, Osiman R, Zhao H, Tuhuti A, Abdunaimu M, Wang H, Jin X, Xing S. lodine nutrition status and thyroid disorders: a crosssectional study from the Xinjiang Autonomous Region of China. Eur j Clin Nutr. 2016;70:1332.

7. Hammiche F, Laven JS, Twigt J, Bolleaard WP, Steegers EA, Steergers-Theunissen RP. Body mass index and central adiposity are associated with sperm quality in men of subfertile couples. Hum reprod. 2012;27:2365-72.

8. lodine Global Network. http://www.ign.org/index.cfm.

9. Jorgensen N, Andersen AG, Eustache F. Regional differences in semen quality in Europe. Hum Reprod. 2001;16:1012-9.

10. Leung AM, Braverman LE. Consequences of excess iodine. Nat Rev Endocr. 2014;10:136.

11. Mahapatra D, Chandra AK. Biphasic action of iodine in excess at different doses on ovary in adult rats. J Trace Elem Med Biol. 2017;39:210-20.

12. Meikle AW. The interrelationships between thyroid dysfunction and hypogonadism in men and boys Thyroid 2004; 14Suppl: 17-25.

13. Eisenberg ML, Kim S, Chen Z, Sundaram R, Schisterman EF. Louis GM The relationship between male BMI and waist circumference on semen quality: data from the LIFE study. Hum Reprod. 2014;29:193-200.

14. Partal-Lorente AB, Maldonado-Ezequiel V, Martinez-Navarro L, et al. lodine is associated to semen quality in men who undergo consultations for infertility. Reprod Toxico. 2017;73:1-7.

15. Pino S, Fang SL, Braverman LE. Braverman. Ammonium persulfate: a safe alternative oxidizing reagent for measuring urinary iodine. Clin chem. 1996;42:239-43. 
16. Rasmussen LB, Ovesen L, Christiansen E. Day-to-day and within-day variationin urinary iodine excretion. Eur J Clin Nutr. 1999;53:401-7.

17. Rohner F, Zimmermann M, Jooste P. Biomarkers of Nutrition for Development-lodine. Review J Nutr. 2014;144:1322S-1342S.

18. Rossi AC, Tomimori E, Camargo R, Medeiros-Neto G. Searching for iodine deficiency disorders in schoolchildren from Brazil: the thyromobil project Thyroid 2001;11:661-663.

19. Sakamoto KQ, Ishizuka M, Kazusaka A, Fujita S. lodine intake as a possible cause of discontinuous decline in sperm counts: a re-evaluation of historical and geographic variation in semen quality. Jpn J Vet Res. 2004;52(2):85-94.

20. Stokes-Riner A, Thurston SW, Brazil C, Guzick D, Liu F, Overstreet JW, et al. One semen sample or 2? Insights from a study of fertile men. J Androl. 2007;28:638-43.

21. Swan SH, Elkin EP, Fenster L. Have Sperm Densities Declined? A Reanalysis of Global Trend Data. Environ Health Perspe. 1997;105:1228-36.

22. Swan SH, Elkin EP, Fenster L. The Question of Declining Sperm Density Revisited: An Analysis of 101 Studies Published 1934-1996. Environ Health Perspe. 2000;108:961-6.

23. Teng W, Shan Z, Teng X, Guan H, Li Y, Teng D, et al. Effect of iodine intake on thyroid diseases in China. N Engl J Med. 2006;354:2783-93.

24. Vieria M. New World Health Organization reference values for semen analysis: Where do we stand? Hum Reprod Update. 2010;16(3):231-45.

25. Virtanen HE, Jørgensen N, Toppari J. Semen quality in the 21st century. Nat Rev Urol. 2017;14:120.

26. World Health Organization. and UNICEF. Progress towards the elimination of iodine deficiency disorders (IDD). 1999.

27. World Health Organization. Assessment of iodine deficiency disorders and monitoring their elimination: a guide for programme managers. 3 rd ed; 2007.

28. World Health Organization DoRHaR. WHO Laboratory Manual for the Examination and Processing of Human Semen, 5th ed; 2010.

29. Xiao DL, Sun DJ, Bai HQ, Liu SJ. Monitoring of iodine deficiency disease in China People's Beijing, China, Medical Publishing House, 2005.

30. Zimmermann MB, Andersson M. Assessment of iodine nutrition in populations: past, present, and future. Nutr rev. 2012;10:553-70.

\section{Tables}

Table 1 Baseline characteristics of volunteers by UIC group. 


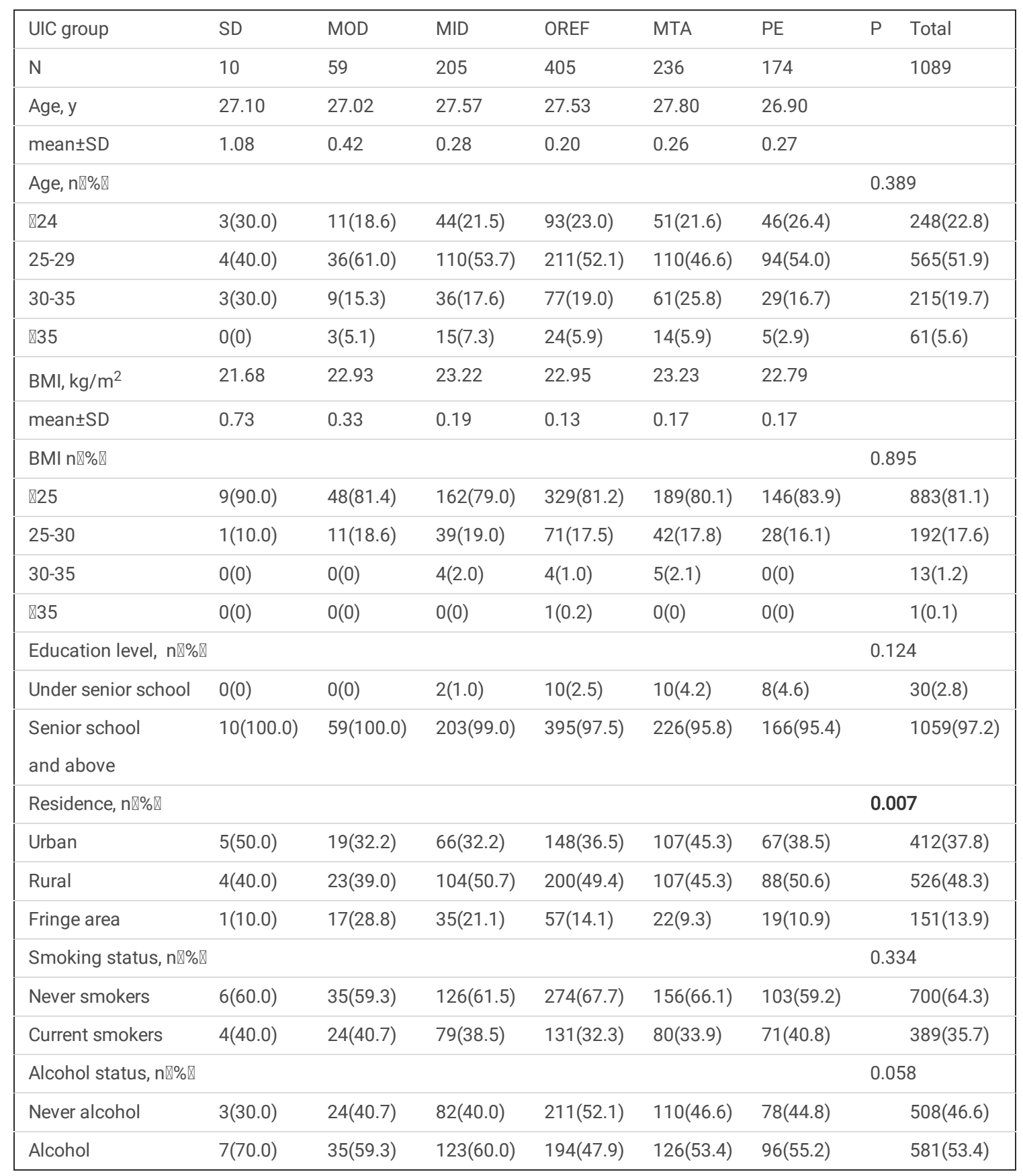

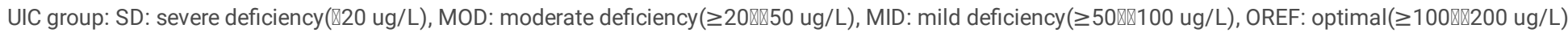

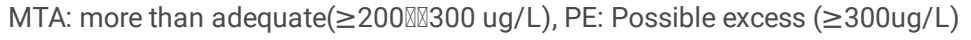

Table 2 Baseline characteristics of reproductive and semen parameters by UIC group. 


\begin{tabular}{|c|c|c|c|c|c|c|c|c|}
\hline UIC group & SD & MOD & MID & OREF & MTA & $\mathrm{PE}$ & $\mathrm{P}$ & Total \\
\hline \multicolumn{6}{|c|}{ Pregnant history, $\mathrm{n} \rrbracket \% \bigotimes$} & \multicolumn{3}{|c|}{0.759} \\
\hline$\leq 2$ & 10(100) & $56(94.9)$ & 191(93.2) & $379(93.6)$ & 219(92.8) & $158(90.8)$ & & 1013(93.0) \\
\hline$\llbracket 3$ & $0(0)$ & $3(5.1)$ & $14(6.8)$ & $26(6.4)$ & $17(7.2)$ & 16(9.2) & & $76(7.0)$ \\
\hline \multicolumn{6}{|c|}{ Birth history, y, $n \rrbracket \% \bigotimes$} & \multicolumn{3}{|c|}{0.238} \\
\hline$\otimes 1$ & $8(80.0)$ & $48(21.4)$ & $162(79.0)$ & $319(78.8)$ & 169(71.6) & $140(80.5)$ & & $846(78.7)$ \\
\hline$\geq 1$ & $2(20.0)$ & 11(18.6) & $43(21.0)$ & $86(21.2)$ & $67(28.4)$ & $34(19.5)$ & & $243(22.3)$ \\
\hline \multicolumn{6}{|c|}{ TTP, month , nヌ\%区 } & \multicolumn{3}{|c|}{0.000} \\
\hline \12 & $7(70)$ & $46(78.0)$ & $168(82.0)$ & 395(97.5) & $230(97.5)$ & 149(85.6) & & 995(91.4) \\
\hline$\geq 12$ & $3(30)$ & $13(22.0)$ & $37(18.0)$ & $10(2.5)$ & $6(2.5)$ & $25(14.4)$ & & $94(8.6)$ \\
\hline \multicolumn{6}{|c|}{ Abstinence period, day, $\mathrm{n} \otimes \% \bigotimes$} & \multicolumn{3}{|c|}{0.412} \\
\hline $2-3$ & $1(10.0)$ & $15(25.4)$ & $36(17.6)$ & $68(16.8)$ & $44(18.6)$ & 19(10.9) & & 183(16.8) \\
\hline $3-5$ & $7(70.0)$ & $31(52.5)$ & 131(63.9) & $254(62.7)$ & $147(62.3)$ & 123(70.7) & & 693(63.6) \\
\hline $5-7$ & $2(20.0)$ & $13(22.1)$ & $38(18.5)$ & $83(20.5)$ & $45(19.1)$ & $32(18.4)$ & & 213(19.6) \\
\hline Media(IQR) & $4(3,4.625)$ & $4(2.5,5.0)$ & $4(3,5)$ & $4(3,5)$ & $4(3,5)$ & $4(3,5)$ & & \\
\hline \multicolumn{6}{|c|}{ Semen volume,ml, $\mathrm{n} \nabla \% \nabla$} & \multicolumn{3}{|c|}{0.7} \\
\hline$\otimes 1.5$ & $1(10.0)$ & $3(5.1)$ & $11(5.4)$ & $29(7.2)$ & $14(5.9)$ & $7(4.0)$ & & $65(6.0)$ \\
\hline$\geq 1.5$ & $9(90.0)$ & $56(94.9)$ & 194(94.6) & $376(92.8)$ & 222(94.1) & 167(96.1) & & $1024(94.0)$ \\
\hline Media(IQR) & $2.65(2.38,3.75)$ & $3.00(2.50,3.60)$ & $2.80(2.25,2.85)$ & $2.7(2.1,3.5)$ & $2.9(2.2,3.79)$ & $2.85(2.3,3.83)$ & & \\
\hline \multicolumn{6}{|l|}{ Semen pH } & \multicolumn{3}{|c|}{0.026} \\
\hline$\leq 7.2$ & $4(40.0)$ & $34(57.6)$ & 104(50.7) & 202(49.9) & $101(42.8)$ & $66(37.9)$ & & $511(46.9)$ \\
\hline$\otimes 7.2$ & $6(60.0)$ & $25(43.4)$ & $101(49.3)$ & 203(50.1) & $135(57.2)$ & $108(62.1)$ & & $578(53.1)$ \\
\hline \multicolumn{6}{|c|}{ Sperm concentration, $\times 10^{6} / \mathrm{ml}, \mathrm{n} \rrbracket \% \rrbracket$} & \multicolumn{3}{|c|}{0.000} \\
\hline Q15 & $1(10.0)$ & $5(8.5)$ & 18(8.8) & $2(0.5)$ & $3(1.3)$ & 17(9.8) & & $46(4.2)$ \\
\hline$\geq 15$ & $9(90.0)$ & $54(91.5)$ & 187(91.2) & 403(99.5) & 233(98.7) & 157(90.2) & & 1043(95.8) \\
\hline \multirow[t]{2}{*}{ Media(IQR) } & 35.75 & $36.5(24,46)$ & $42(28.25,54)$ & $62(44,90)$ & $59(41,84.75)$ & \multirow{2}{*}{\multicolumn{2}{|c|}{$44(28.75,59.5)$}} & \\
\hline & $(20.88,47.25)$ & & & & & & & \\
\hline \multicolumn{6}{|c|}{ Total sperm count, $\times 10^{6}, \mathrm{n} \rrbracket \% \rrbracket$} & \multicolumn{3}{|c|}{0.000} \\
\hline$\varangle 39$ & $2(20.0)$ & $6(10.2)$ & $21(10.2)$ & $5(1.2)$ & $4(1.7)$ & $17(9.8)$ & & $55(5.1)$ \\
\hline$\geq 39$ & $8(80.0)$ & $53(89.8)$ & 184(89.8) & $400(98.8)$ & 232(98.3) & 157(90.2) & & $1034(94.9)$ \\
\hline \multirow[t]{2}{*}{ Media(IQR) } & 112.88 & 107.20 & 120.4 & 165.2 & 178.35 & 122.25 & & \\
\hline & $(42.08,187.88)$ & $(60.00,164.15)$ & $(73,183.6)$ & $(107.2,264.8)$ & $(102.13,244.85)$ & $(83.11,191.29)$ & & \\
\hline \multicolumn{6}{|c|}{ Total motility (\%) } & \multicolumn{3}{|c|}{0.570} \\
\hline$\nabla 40$ & $0(0)$ & $10(16.9)$ & $23(11.2)$ & $53(13.1)$ & $36(15.3)$ & $22(12.6)$ & & $144(13.2)$ \\
\hline$\geq 40$ & $10(100)$ & $49(83.1)$ & 182(88.8) & $352(86.9)$ & $200(84.7)$ & $152(87.4)$ & & $945(86.8)$ \\
\hline Media(IQR) & $49(42.25,57.50)$ & $50(43,60)$ & $52(45,60)$ & $51(43,62.5)$ & $52(42,60)$ & $50(44,58)$ & & \\
\hline \multicolumn{6}{|c|}{ Progressive motility(PR) (\%) } & \multicolumn{3}{|c|}{0.948} \\
\hline 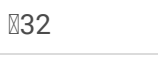 & $1(10.0)$ & $10(16.9)$ & $30(14.6)$ & $68(16.8)$ & $42(17.8)$ & $28(16.1)$ & & $179(16.4)$ \\
\hline$\geq 32$ & $9(90.0)$ & $49(83.1)$ & 175(85.4) & $337(83.2)$ & 194(82.2) & 146(83.9) & & $910(83.6)$ \\
\hline \multicolumn{6}{|c|}{ None progressive motility(NP) (\%) } & & 0.104 & \\
\hline$\otimes 1$ & $1(10.0)$ & $3(5.1)$ & $4(2.0)$ & $6(1.5)$ & $2(0.8)$ & $3(1.7)$ & & 19(1.7) \\
\hline$\geq 1$ & $9(90.0)$ & $56(94.9)$ & 201(98.0) & 399(98.5) & 234(99.2) & 171(98.3) & & $1070(98.3)$ \\
\hline
\end{tabular}




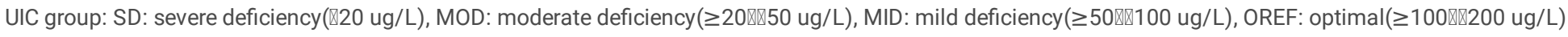
MTA: more than adequate $(\geq 2008 \mathbb{3 0 0} \mathrm{ug} / \mathrm{L})$, PE: possible excess $(\geq 300 \mathrm{ug} / \mathrm{L})$

Table 3 Association between semen quality parameters and higher UIC (continuous outcomes)

\begin{tabular}{|c|c|c|c|c|c|c|c|c|}
\hline Category & Volume (ml) & $\begin{array}{l}\text { Total } \\
\text { Motility }\end{array}$ & Semen $\mathrm{pH}$ & PR & NP & IM & $\begin{array}{l}\text { Semen } \\
\text { concentration }\end{array}$ & Total sperm col \\
\hline OREF & $2.7(2.1,3.5)$ & $51(43,62.5)$ & 7.3(7.2,7.5) & $44.57(36.12,53.50)$ & $6.57(3.97,9.84)$ & $49.00(37.55,57.03)$ & $62(44,90)$ & $165.2(107.2,26$ \\
\hline MTA & $2.9(2.2,3.8)$ & $52(42,60)$ & 7.3(7.2,7.5) & $44.86(35.74,52.50)$ & $6.73(4.09,9.27)$ & $48.01(40.08,58.08)$ & $59(41,84.75)$ & 178.35(102.13,: \\
\hline PE & $2.85(2.3,3.83)$ & $50(44,58)$ & $7.3(7.2,7.6)$ & $44.19(36.47,51.10)$ & $6.21(3.67,9.64)$ & $50(41.89,55.97)$ & $44(28.75,59.5)$ & 122.25(83.11,1' \\
\hline $\begin{array}{l}\text { P-model } \\
1\end{array}$ & 0.148 & 0.740 & & 0.704 & & 0.741 & 0.000 & 0.000 \\
\hline $\begin{array}{l}\text { P-model } \\
2\end{array}$ & 0.201 & 0.462 & & 0.101 & & 0.462 & 0.000 & 0.000 \\
\hline
\end{tabular}

$P$ value for trend test based on linear models. Linear regression was performed to analyze semen parameters. Model 1 was unadjusted and model 2 adjusted

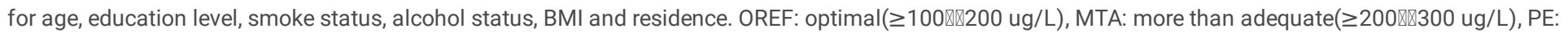
possible excess $(\geq 300 \mathrm{ug} / \mathrm{L})$

Table 4 Association between abnormal semen quality parameters and higher UIC continuous outcomes (\%)

\begin{tabular}{|c|c|c|c|c|c|c|c|c|c|}
\hline Category & $\begin{array}{l}\text { Semen } \\
\text { volume }\end{array}$ & $\begin{array}{l}\text { Total } \\
\text { Motility }\end{array}$ & Semen $\mathrm{pH}$ & PR & NP & $\mathrm{IM}$ & $\begin{array}{l}\text { Semen } \\
\text { concentration }\end{array}$ & $\begin{array}{l}\text { Total sperm } \\
\text { count }\end{array}$ & TTP \\
\hline & $\leq 1.5 \mathrm{ml}$ & $\varangle 40$ & $\leq 7.2$ & $₫ 32$ & $\otimes 1$ & $\varangle 22$ & $\otimes 15 \times 10^{6} / \mathrm{ml}$ & $\llbracket 39 \times 10^{6}$ & $\begin{array}{l}\otimes 12 \\
\text { months }\end{array}$ \\
\hline OREF & $29(7.16)$ & $53(13.09)$ & $202(49.87)$ & $68(16.79)$ & $6(1.48)$ & $2(0.49)$ & $2(0.49)$ & $5(1.23)$ & $10(2.47)$ \\
\hline MTA & $14(5.93)$ & $36(15.25)$ & $101(42.80)$ & $42(17.80)$ & $2(0.85)$ & $2(0.85)$ & $3(1.27)$ & $4(1.69)$ & $6(2.54)$ \\
\hline $\mathrm{PE}$ & $7(4.02)$ & $22(12.64)$ & $66(37.93)$ & $28(16.09)$ & $3(1.72)$ & $0(0)$ & 17(9.77) & 17(9.77) & $25(14.39)$ \\
\hline $\begin{array}{l}\text { P-trend model } \\
1\end{array}$ & 0.329 & 0.597 & & 0.570 & 0.713 & 0.322 & 0.000 & 0.000 & 0.000 \\
\hline $\begin{array}{l}\text { P-trend model } \\
2\end{array}$ & 0.361 & 0.646 & 0.030 & 0.497 & 0.645 & 0.256 & 0.000 & 0.000 & 0.000 \\
\hline
\end{tabular}

Semen was dichotomized as normal or abnormal according to WHO standard

$P$ value for trend test based on linear models. Linear regression was performed to analyze semen parameters. Model 1 was unadjusted model and model 2 adjusted for age, education level, smoke status, alcohol status, BMI and residence. OREF: optimal( $\geq 100 \otimes \otimes 200$ ug/L), MTA: more than adequate( $\geq 200 \otimes \otimes 300$ ug/L), PE: possible excess( $\geq 300 u g / L)$

Table 5. The association between higher UIC and the likelihood of having abnormal semen parameters by category outcomes

\begin{tabular}{|c|c|c|c|c|c|c|c|c|c|c|}
\hline \multicolumn{2}{|l|}{ Category } & volume & $\begin{array}{l}\text { Total } \\
\text { Motility }\end{array}$ & $\begin{array}{l}\text { Semen } \\
\mathrm{pH}\end{array}$ & PR & NP & $\mathrm{IM}$ & $\begin{array}{l}\text { Semen } \\
\text { concentration }\end{array}$ & $\begin{array}{l}\text { Total sperm } \\
\text { count }\end{array}$ & TTP \\
\hline & & $\leq 1.5 \mathrm{ml}$ & $\otimes 40$ & $\leq 7.2$ & $凶 32$ & $\nabla 1$ & $\otimes 22$ & $\triangle 15 \times 10^{6} / \mathrm{ml}$ & $\nabla 39 \times 10^{6}$ & $\begin{array}{l}\bigotimes 12 \\
\text { months }\end{array}$ \\
\hline OREF & & reference & reference & & reference & reference & reference & reference & reference & reference \\
\hline MTA & $\mathrm{Cl}$ & 0.82 & 1.20 & 0.75 & 1.07 & 0.57 & 1.72 & 2.59 & 1.38 & 1.03 \\
\hline model 1 & $95 \mathrm{Cl}$ & $\begin{array}{l}0.42- \\
1.58\end{array}$ & $0.76-1.89$ & $0.54-1.04$ & $\begin{array}{l}0.70- \\
1.64\end{array}$ & $\begin{array}{l}0.117- \\
2.84\end{array}$ & $\begin{array}{l}0.24- \\
12.31\end{array}$ & $0.43-15.64$ & $0.37-5.19$ & $0.37-2.87$ \\
\hline PE & $\mathrm{Cl}$ & 0.54 & 0.96 & 0.61 & 0.95 & 1.17 & & 21.82 & 8.66 & 6.63 \\
\hline model 2 & $95 \mathrm{Cl}$ & $\begin{array}{l}0.23- \\
1.27\end{array}$ & $0.57-1.64$ & $0.43-0.88$ & $\begin{array}{l}0.59- \\
1.54\end{array}$ & $0.29-4.72$ & & $4.98-95.53$ & $3.14-23.88$ & $3.11-14.13$ \\
\hline MTA & $\mathrm{Cl}$ & 0.83 & 1.244 & 0.75 & 1.06 & 0.57 & 1.37 & 2.33 & 1.45 & 0.99 \\
\hline model 2 & $95 \mathrm{Cl}$ & $\begin{array}{l}0.42- \\
1.62\end{array}$ & $0.78-1.98$ & $0.54-1.05$ & $\begin{array}{l}0.69- \\
1.63\end{array}$ & $0.11-2.90$ & $\begin{array}{l}0.18- \\
10.25\end{array}$ & $0.38-14.22$ & $0.38-5.54$ & $0.35-2.82$ \\
\hline PE & $\mathrm{Cl}$ & 0.56 & 0.99 & 0.64 & 0.92 & 1.02 & & 18.53 & 8.64 & 7.49 \\
\hline model 2 & $95 \mathrm{Cl}$ & $\begin{array}{l}0.24- \\
1.32\end{array}$ & $0.58-1.71$ & $0.44-0.92$ & $\begin{array}{l}0.56- \\
1.50\end{array}$ & $0.24-4.25$ & & $4.20-81.73$ & $3.07-24.34$ & $3.34-16.80$ \\
\hline
\end{tabular}


Semen parameters was dichotomized per WHO standard. Multivariable logistic regression was performed for estimating ORs. Model 1 was cruded model and

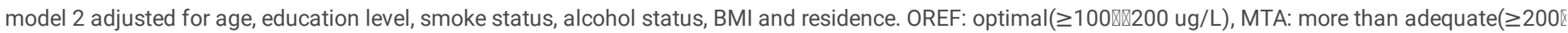
$₫ 300 \mathrm{ug} / \mathrm{L}), \mathrm{PE}:$ possible excess( $\geq 300 \mathrm{ug} / \mathrm{L})$

Table 6 Association between semen quality parameters and deficient UIC (continuous outcomes)

\begin{tabular}{|c|c|c|c|c|c|c|c|}
\hline Category & Volume (ml) & Total Motility & Semen $\mathrm{pH}$ & PR & NP & $\mathrm{IM}$ & $\begin{array}{l}\text { Semen } \\
\text { concentration }\end{array}$ \\
\hline SD & $2.65(2.375,3.75)$ & $49.00(42.25,57)$ & $7.45(7.00,7.70)$ & $45.84(37.44,54.66)$ & $4.15(1.86,8.80)$ & $51.01(42.44,57.77)$ & $30.75(25.88,47.25)$ \\
\hline MOD & $3.0(2.5,3.6)$ & $50.00(43,60)$ & $7.2(7.2,7.6)$ & $44.78(34.57,51.90)$ & $7.19(4.24,10.28)$ & $50(40,57.07)$ & $36.50(24.00,46.00)$ \\
\hline MID & $2.80(2.25,3.85)$ & $52(45,60)$ & 7.2(7.2,7.55) & $44.31(36.59,52.56)$ & $6.52(4.29,10.04)$ & $47.93(39.93,55.03)$ & $42(28.25,54)$ \\
\hline OREF & $2.7(2.1,3.5)$ & $51(43,62.5)$ & $7.3(7.2,7.5)$ & $44.57(36.12,53.50)$ & $6.57(3.97,9.84)$ & $49.00(37.55,57.03)$ & $62(44,90)$ \\
\hline $\begin{array}{l}\text { P-Trend } \\
\text { model } 1\end{array}$ & 0.105 & 0.790 & 0.963 & 0.749 & 0.859 & 0.792 & 0.000 \\
\hline $\begin{array}{l}\text { P-Trend } \\
\text { model } 2\end{array}$ & 0.598 & 0.448 & 0.22 & 0.219 & 0.088 & 0.445 & 0.000 \\
\hline
\end{tabular}

$P$ value for trend test based on linear models. Linear regression was performed to analyze semen parameters. Model 1 was unadjusted and model 2 adjusted

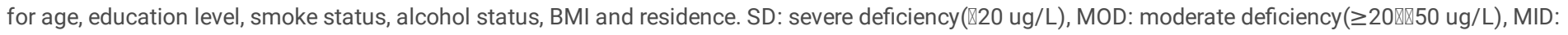

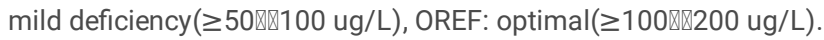

Table 7 Association between abnormal semen quality parameters and deficient UIC (continuous outcomes \%)

\begin{tabular}{|c|c|c|c|c|c|c|c|c|c|}
\hline Category & $\begin{array}{l}\text { Semen } \\
\text { volume }\end{array}$ & Semen pH & $\begin{array}{l}\text { Total } \\
\text { Motility }\end{array}$ & PR & NP & IM & $\begin{array}{l}\text { Semen } \\
\text { concentration }\end{array}$ & $\begin{array}{l}\text { Total sperm } \\
\text { count }\end{array}$ & TTP \\
\hline & $\leq 1.5 \mathrm{ml}$ & $\nabla 40$ & $\leq 7.2$ & $\varangle 32$ & $\nabla 1$ & $\otimes 22$ & $\otimes 15 \times 10^{6} / \mathrm{ml}$ & $\nabla 39 \times 10^{6}$ & $\begin{array}{l}\otimes 12 \\
\text { months }\end{array}$ \\
\hline SD & $1(10)$ & $4(40)$ & $0(0)$ & $1(10)$ & $1(10)$ & $0(0)$ & $1(10)$ & $2(20)$ & $3(30)$ \\
\hline MOD & $3(5.08)$ & $34(57.62)$ & $10(16.94)$ & $10(16.94)$ & $3(5.08)$ & $1(1.69)$ & $5(8.47)$ & $6(10.16)$ & $13(22.03)$ \\
\hline MID & $11(5.36)$ & $104(50.73)$ & $23(11.22)$ & $30(14.63)$ & $4(1.95)$ & $1(0.49)$ & 18(8.78) & $21(10.24)$ & $37(18.05)$ \\
\hline OREF & $29(7.16)$ & $202(49.87)$ & $53(13.09)$ & $68(16.79)$ & $6(1.48)$ & $2(0.49)$ & $2(0.49)$ & $5(1.23)$ & $10(2.47)$ \\
\hline $\begin{array}{l}\text { P-trend model } \\
1\end{array}$ & 0.830 & 0.440 & 0.996 & 0.816 & 0.989 & 0.349 & 0.000 & 0.000 & 0.000 \\
\hline $\begin{array}{l}\text { P-trend model } \\
2\end{array}$ & 0.735 & 0.258 & 0.979 & 0.623 & 0.065 & 0.349 & 0.000 & 0.000 & 0.000 \\
\hline
\end{tabular}

Semen was dichotomized as normal or abnormal according to WHO standard.

P value for trend test based on linear models. Linear regression was performed to analyze semen parameters. Model 1 was unadjusted model and model 2 adjusted for age, education level, smoke status, alcohol status, BMI and residence.

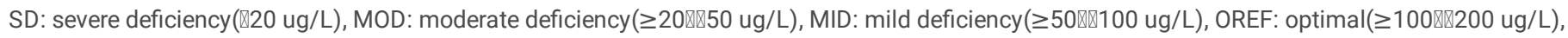

Table 8, the association between deficient UIC and the likelihood of having abnormal semen parameters by category outcomes 


\begin{tabular}{|c|c|c|c|c|c|c|c|c|c|c|}
\hline Category & & volume & $\begin{array}{l}\text { Total } \\
\text { Motility }\end{array}$ & $\begin{array}{l}\text { Semen } \\
\mathrm{pH}\end{array}$ & PR & NP & $\mathrm{IM}$ & $\begin{array}{l}\text { Semen } \\
\text { concentration }\end{array}$ & $\begin{array}{l}\text { Total sperm } \\
\text { count }\end{array}$ & TTP \\
\hline & & $\leq 1.5 \mathrm{ml}$ & $\triangle 40$ & $\leq 7.2$ & $\nabla 32$ & $\otimes 1$ & $\varangle 22$ & $\nabla 15 \times 10^{6} / \mathrm{ml}$ & $\otimes 39 \times 10^{6}$ & $\begin{array}{l}\otimes 12 \\
\text { months }\end{array}$ \\
\hline SD & $\mathrm{Cl}$ & 1.44 & 0 & 0.67 & 0.55 & 7.39 & 0 & 22.84 & 20.00 & 16.93 \\
\hline model 1 & $95 \mathrm{Cl}$ & $\begin{array}{l}0.18^{-} \\
11.77\end{array}$ & & $0.19-2.41$ & $\begin{array}{l}0.07- \\
4.42\end{array}$ & $\begin{array}{l}0.80- \\
67.88\end{array}$ & & $1.86-269.95$ & 3.36-11.-8.94 & $3.81-75.19$ \\
\hline MOD & $\mathrm{Cl}$ & 0.70 & 1.36 & 1.37 & 1.016 & 3.56 & 3.47 & 18.66 & 9.06 & 11.63 \\
\hline model 1 & $95 \mathrm{Cl}$ & $0.21-2.36$ & $0.65-2.84$ & $0.79-2.37$ & $\begin{array}{l}0.49- \\
2.10\end{array}$ & $\begin{array}{l}0.87- \\
14.65\end{array}$ & $\begin{array}{l}0.31- \\
38.92\end{array}$ & 3.35-98.54 & $2.67-30.70$ & $4.63-26.89$ \\
\hline MID & $\mathrm{Cl}$ & 0.74 & 0.84 & 1.04 & 0.85 & 1.32 & 0.99 & 19.40 & 9.13 & 8.67 \\
\hline model 1 & $95 \mathrm{Cl}$ & $0.36-1.50$ & $0.50-1.41$ & $0.74-1.45$ & $\begin{array}{l}0.53- \\
1.36\end{array}$ & $0.37-4.74$ & $\begin{array}{l}0.09- \\
10.96\end{array}$ & $4.46-84.45$ & 3.39-24.59 & $4.23-17.90$ \\
\hline SD & $\mathrm{Cl}$ & 1.14 & 0 & 0.69 & 0.47 & 9.15 & 0 & 27.35 & 24.555 & 19.40 \\
\hline model 2 & $95 \mathrm{Cl}$ & $0.13-9.77$ & & $0.19-2.51$ & $\begin{array}{l}0.06- \\
3.88\end{array}$ & $\begin{array}{l}0.88- \\
95.56\end{array}$ & & $2.12-353.62$ & $3.85-156.38$ & $4.17-90.20$ \\
\hline MOD & $\mathrm{Cl}$ & 0.73 & 1.34 & 1.45 & 0.95 & 3.28 & 3.65 & 12.97 & 7.11 & 10.52 \\
\hline model 2 & $95 \mathrm{Cl}$ & $0.21-2.52$ & $0.63-2.82$ & $0.84-2.58$ & $\begin{array}{l}0.45- \\
1.98\end{array}$ & $\begin{array}{l}0.77- \\
14.05\end{array}$ & $\begin{array}{l}0.32- \\
42.28\end{array}$ & $2.34-71.41$ & $2.03-24.91$ & $4.29-25.78$ \\
\hline MID & $\mathrm{Cl}$ & 0.75 & 0.85 & 1.07 & 0.84 & 1.37 & 1.02 & 17.00 & 8.68 & 8.44 \\
\hline model 2 & $95 \mathrm{Cl}$ & $0.37-1.55$ & $0.50-1.44$ & $0.76-1.50$ & $\begin{array}{l}0.52- \\
1.35\end{array}$ & $0.38-4.99$ & $\begin{array}{l}0.09- \\
11.57\end{array}$ & $3.85-75.07$ & $3.18-23.70$ & 4.07-17.49 \\
\hline OREF & & reference & reference & reference & reference & reference & reference & reference & reference & reference \\
\hline
\end{tabular}

Semen parameters was dichotomized per WHO standard. Multivariable logistic regression was performed for estimating ORs. Model 1 was cruded model and model 2 adjusted for age, education level, smoke status, alcohol status, BMI and residence. SD: severe deficiency( $₫ 20 \mathrm{ug} / \mathrm{L}), \mathrm{MOD}: \mathrm{moderate}$ deficiency $(\geq 20 \otimes \square$ 50 ug/L), MID: mild deficiency( $\geq 50 \otimes \otimes 100$ ug/L), OREF: optimal( $\geq 1008 \otimes 200$ ug/L), 